
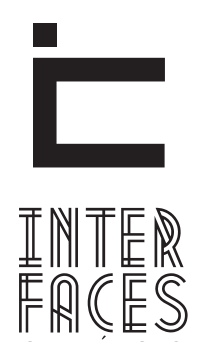

CIENTÍFICAS

HUMANAS E SOCIAIS

ISSN IMPRESSO 2316-3348

E-ISSN 2316-3801

DOI - 10.17564/2316-3801.2017v6n1p33-46

\title{
DESIGUALDADE DE GÊNERO: UMA ANÁLISE DA EXCLUSÃO DA MULHER NO PROCESSO DE IMPLEMENTAÇ̃̃O DAS APACS NO BRASIL
}

GENDER INEQUALTTY: AN ANALYSIS OF WOMEN'S EXCLUSION ABOUT PROCESS OF APAC IMPLEMENTATION IN BRAZLL

DESIGUALDAD DE GÉNERO: UN ANÁLISIS DE LA EXCLUSIÓN DE LA MUJER EN PROCESO DE APLICACIÓN DE LAS APACS EN BRASIL

\section{RESUMO}

0 presente artigo aborda a desproporção existente quando comparado o número de unidades APACs femininas no Brasil com o número de unidades masculinas, analisando-se, ainda, a influência da desigualdade de gênero neste contexto de exclusão feminina. O desenvolvimento deste trabalho pauta-se em análise de dados provenientes do Sistema Nacional de Informações Penitenciárias (INFOPEN) e do site do Tribunal de Justiça de Minas Gerais (TJ/MG), onde há a descrição do número de APACs existentes no Brasil. A partir dos números obtidos, resta clara a exclusão da mulher, tanto no número de presídios femininos existentes, quanto no processo de implementação do
Método Apaqueano. Busca-se, com o estudo, tratar da relação entre a desigualdade de gênero existente na sociedade brasileira e a invisibilização da mulher em situação de prisão, tratando das necessidades específicas do gênero feminino no âmbito prisional. Soma-se a isso, a inexistência de políticas públicas voltadas para um tratamento específico das reclusas, inviabilizando a garantia de reinserção social.

\section{PALAVRAS-CHAVE}

Desigualdade de Gênero. Método APAC. Mulher em Situação de Prisão. 


\section{ABSTRACT}

This article discusses the disparity when comparing the number of female APAC units in Brazil with the number of male units, analyzing also the influence of gender inequality in this female exclusion context. The development of this work is guided by analysis of data from the National Penitentiary Information System (INFOPEN) and the website of the Court of Minas Gerais (TJ / MG), where there is the description of the number of APAC in Brazil. From the figures obtained, it remains clear exclusion of women, both in the number of women's prisons, as in the implementation of the method Apaqueano process. Seeks, on this study, dealing with the relation between the gender inequality in Brazilian society and women's invisibility in prison situation, defining the specific needs of females in the prison context. Added to this, the lack of public policies for specific treatment of women prisoners, making it impossible to guarantee social reintegration.

\section{KEYWORDS}

Gender Inequality. APAC method. Women in Prison Situation.

\section{RESUMEN}

En este artículo se analiza la disparidad en comparación con el número de unidades de APAC femeninas en Brasil con el número de unidades para los hombres, analizando también la influencia de la desigualdad de género en el contexto de exclusión femenina. El desarrollo de este trabajo es guiado por el análisis de los datos del Sistema Penitenciario Nacional de Información (InfoPen) y el sitio web del Tribunal de Justicia de Minas Gerais (TJ/MG), donde hay una descripción del número de APAC en Brasil. A partir de los datos obtenidos, queda claro la exclusión de las mujeres, tanto en el número de cárceles de mujeres, y en la implementación del proceso de método de las APCs. Se busca, para el estudio, que trata de la relación entre la desigualdad de género existente en la sociedad brasileña y la invisibilidad de las mujeres en situación de prisión, frente a las necesidades específicas de las mujeres en el contexto penitenciario. Sumado a esto, la falta de políticas públicas para el tratamiento específico de los presos, por lo que es imposible garantizar la reinserción social.

\section{PALABRAS CLAVE}

Desigualdad de género. Método APAC. Mujeres en la cárcel. 


\section{INTRODUÇÃ̃O}

O tema refere-se à desigualdade de gênero existente na implementação das Associação de Proteção e Assistência aos Condenados (APAC) - no Brasil. De acordo com dados do Tribunal de Justiça de Minas Gerais ${ }^{1}$, existem, no Estado, 39 unidades APAC em funcionamento e 58 em fase de implementação. Desse total de 97 APAC, apenas 7 são femininas, fato que demonstra a exclusão da mulher nesse cenário de recuperação. No Brasil as APAC também estão operando no Distrito Federal, Espírito Santo, Maranhão, Rio Grande do Norte, Mato Grosso, Paraná e Rio Grande do Sul, entretanto em nenhum destes Estados temos uma APAC feminina em funcionamento (PORTAL..., on-line).

Faz-se imprescindível para o entendimento desta pesquisa o papel da mulher na sociedade brasileira. A abordagem do trabalho em tela iniciar-se-á a partir da análise de doutrinas feministas, objetivando-se, assim, destacar a importância da consciência feminista para 0 enfrentamento à desigualdade de gênero. Afinal, essa desigualdade reflete-se no Sistema Penitenciário brasileiro, onde a mulher é duplamente subjugada pela sociedade. Primeiramente, simplesmente pela condição do "ser mulher" e, em segundo lugar, por quebrar o estereótipo de delicadeza servil (nasceu para servir ao marido, à casa e aos filhos) ao cometer um crime.

A quantidade de presídios femininos construídos em nosso país não corresponde à quantidade de mulheres presas. De acordo com dados do Ministério da Justiça, no ano de 2014 (BRASIL, 2014), o número de mulheres presas era de aproximadamente 33.793 , o que representa cerca de 5,8\% da população carcerária nacional, mas crescimento do número de mulheres encarceradas é da ordem de $10,7 \%$ ao ano, bem superior à taxa de crescimento do número total de presos, de $7 \%$. Entretanto, as vagas disponíveis no país para as mulheres comportam um total de aproximadamente 22.583 detentas, o que representa um déficit de 13 mil vagas.

1 Com base nos dados do Tribunal de Justiça do Estado de Minas Gerais. Disponível em: <https://goo.gl/t9XvsF〉. Acesso em 13 fev.2017.
Apesar de integrar um pequeno percentual da população carcerária brasileira, fato que possibilitaria uma administração adequada das penitenciárias femininas, as mulheres encarceradas são submetidas a condições desumanas, demonstrando, portanto, a necessidade de expansão do Método Apaqueano em unidades femininas. Será analisada, em consequência, a influência do referido contexto de desigualdade de gênero na exclusão da mulher no processo de implementação das APAC.

$O$ estudo do tema apresentado demonstra-se extremamente importante em razão da necessidade de visibilidade das questões de gênero, como forma de motivar o enfrentamento à desigualdade existente entre homens e mulheres. Soma-se a isso, a questão penitenciária que não apresenta medidas eficazes de reintegração do indivíduo, submetendo-o à condição de eterna exclusão social. A fusão das duas vertentes descritas remete ao estudo da exclusão feminina no processo de implementação das APAC no Brasil.

Para o desenvolvimento deste trabalho, utilizou-se o método dedutivo, a partir da abordagem geral da desigualdade de gênero existente no Brasil e posterior especificação do tema, ao tratar do reflexo desta desigualdade na implementação de APAC femininas. Além deste método, foi utilizada a pesquisa bibliográfica, principalmente, com o estudo das obras da pesquisadora feminista Judith Butler e do advogado criminalista Mário Ottoboni, possibilitando a interação dos estudos sobre a desigualdade entre homens e mulheres e a importância da utilização do método APAC em um país onde o Sistema Penal mostra-se falido.

\section{ENFRENTAMENTO À DESIGUALDADE DE GÊNERO COMO BUSCA PELO DESENVOLVIMENTO PLENO}

A classificação de um país, em termos de desenvolvimento, ultrapassa a análise do poderio econômico da nação, sendo imprescindível a observação de outros fatores sociais para que o Estado possa ser considerado plenamente desenvolvido. 
No Brasil, objetivos fundamentais da República estão insculpidos no artigo $3^{\circ}$ da Carta Magna. ${ }^{2}$ Ao analisar a norma constitucional citada, conclui-se que o desenvolvimento econômico, trazido pelos incisos II e III, não é tratado de forma exclusiva e única. Em outras palavras, o artigo faz referência ao desenvolvimento nacional, como também à erradicação da pobreza (elementos relacionados ao desenvolvimento econômico), porém, o próprio termo "desenvolvimento nacional" não pode ser entendido apenas como desenvolvimento econômico, mas também como desenvolvimento social e humano.

Nesse mesmo sentido, ao citar a erradicação da pobreza, o dispositivo legal complementa tal objetivo com o comprometimento de erradicar, também, a marginalização, fato relacionado ao desenvolvimento social. Portanto, a Constituição Federal preconiza o desenvolvimento pleno, quando em seus objetivos institui elementos referentes tanto ao desenvolvimento econômico, quanto ao desenvolvimento humano e social.

Entretanto, em contrapartida aos dizeres constitucionais expostos, as desigualdades constituem um sério problema brasileiro. Nesse cenário desigual, destaca-se a desigualdade de gênero, responsável pela vedação de inúmeros direitos às mulheres, tais como: direitos políticos, direitos sexuais, direitos sociais, direito à educação e ao trabalho.

Durante o passar dos anos, com a aquisição de alguns direitos, houve uma transformação nas formas de discriminação da mulher. Atualmente, o direito ao voto é garantido, mas a participação política feminina continua sendo um desafio; o direito ao trabalho foi conquistado, mas a desigualdade salarial entre homens e mulheres faz-se presente; não existe obrigatoriedade de vestimenta para mulher, porém esta continua sendo julgada de acordo com a sua roupa; a vida social não se restringe mais aos afazeres domésticos, entretanto, como consequência, a mulher

2 I - Construir uma sociedade livre, justa e solidária; II - garantir o desenvolvimento nacional; III - erradicar a pobreza e a marginalização e reduzir as desigualdades sociais e regionais; IV - promover o bem de todos, sem preconceitos de origem, raça, sexo, cor, idade e quaisquer outras formas de discriminação (BRASIL, 1988). submete-se à tripla jornada, devido a não participação da grande maioria dos homens na administração do lar e no cuidado com os filhos.

Demonstra-se necessário o combate à desigualdade de gênero, devido à existência de forte misoginia (discursos contra as mulheres) na sociedade brasileira. A referida prática não se mostra sempre de forma explícita, prova disso são as violências simbólicas mascaradas de elogios. 0 rebaixamento da mulher à mera sexualidade, presente em campanhas de publicidade, e a "coisificação" da esposa como propriedade do marido são exemplos de misoginia comumente aceita pela sociedade, tendo em vista a normalidade a partir da qual esses atos são encarados.

A consciência feminista, "que em nossos dias cresce, se desenvolve e adquire enorme importância na arena mundial" (ALAMBERT, 1986, p. 57), constitui elemento indispensável para o combate à desigualdade de gênero e, consequentemente, para o alcance de um maior número de garantias para as mulheres.

Muitas mulheres têm dificuldade de se auto intitularem feministas, devido à ideia equivocada, cultivada pelo senso comum, de que o feminismo é uma ideologia de superioridade da mulher sobre o homem $(\text { femismo })^{3}$. 0 verdadeiro significado de feminismo refere-se a um movimento que busca por fim à hierarquização dos sexos, pauta-se, portanto, no Princípio da Igualdade preconizado na Constituição Federal 4 .

Como produto do referido pensar feminista, surge na sociedade um novo conceito do "ser mulher", nas palavras da feminista Zuleika Alambert (1986, p. 70):

\footnotetext{
3 “[...] o femismo, um neologismo (palavra que não existia anteriormente no português, mas já aceita como nova palavra, geralmente nascida e adaptada a partir de um estrangeirismo) criado para que não houvesse confusão com o feminismo, pois são completamente diferentes. Para o femismo, a libertação da mulher só virá quando a mulher inverter a lógica do patriarcado, construindo uma espécie de sociedade matriarcal, onde as mulheres detenham o poder, para com isso pagar a dívida histórica que a sociedade patriarcal deixou, criando condições para as mulheres manifestarem sua identidade. Resumindo, [...] o femismo é uma reparação mais radical contra a sociedade patriarcal". (ROSSI, 2011, s/p).

4 Art. $5^{\circ}$ Todos são iguais perante a lei, sem distinção de qualquer natureza, garantindo-se aos brasileiros e aos estrangeiros residentes no País a inviolabilidade do direito à vida, à liberdade, à igualdade, à segurança e à propriedade, nos termos seguintes: I - homens e mulheres são iguais em direitos e obrigações, nos termos desta Constituição (BRASIL. Constituição, 1988).
} 
Afinal, o que são essas novas mulheres? [...] Não são as puras e encantadoras jovens cujo romance desemboca num feliz casamento; não são as esposas que sofrem por causa das infidelidades do marido nem as que cometeram adultério. Nem são as velhas donzelas que se lamentam do amor frustrado da juventude, nem as sacerdotisas do amor, as vítimas de singulares condições de vida ou da própria natureza depravada. Não. Trata-se de um quinto tipo de heroína totalmente novo, até agora desconhecido; são as heroínas que têm exigências de independência, que afirmam a sua personalidade, que protestam contra submissão da mulher ao Estado, à família, à sociedade, que lutam pelos seus direitos, enquanto representantes de seu sexo.

A mudança no comportamento social da mulher contribuiu e continua a contribuir com o enfrentamento à desigualdade de gênero. Essa luta pela autonomia feminina busca garantir o exercício pleno de liberdade da mulher. Afinal, "a desigualdade entre homens e mulheres afeta - e às vezes encerra prematuramente - a vida de milhões de mulheres e, de modos diferentes, restringe em altíssimo grau as liberdades substantivas ${ }^{5}$ para o sexo feminino" (SEN, 2000, p. 29).

0 enfrentamento à desigualdade de gênero possui a prerrogativa de garantir a felicidade geral. Nas palavras de Fernando de Brito Alves (2013, p. 56):

A felicidade geral, nessa perspectiva liberal, seria obtida por meio do cálculo utilitário, que equacionasse o maior índice das felicidades particulares. [...] para que haja a maior felicidade possível, cada um em particular deve estar desempenhando sua função social de forma adequada.

Assim, conclui-se que, enquanto forem vedados à mulher direitos fundamentais básicos, indispensáveis para que esta exerça sua função social de cidadã com igualdade, a felicidade geral e o bem-estar de toda sociedade jamais poderão ser atingidos.

De acordo com a Convenção sobre a Eliminação de todas as Formas de Discriminação contra mulher:

\footnotetext{
5 As liberdades substantivas incluem capacidades elementares como por exemplo ter condições de evitar privações como a fome, a subnutrição, a morbidez evitável e a morte prematura, bem como as liberdades associadas a saber ler e fazer cálculos aritméticos, ter participação política e liberdade de expressão etc. (SEN, 2000, p. 52).
}

\begin{abstract}
[...] A discriminação contra a mulher viola os princípios da igualdade de direitos e do respeito da dignidade humana, dificulta a participação da mulher, nas mesmas condições que o homem, na vida política, social, econômica e cultural de seu país, constitui um obstáculo ao aumento do bem-estar da sociedade e da família e dificulta o pleno desenvolvimento das potencialidades da mulher para prestar serviço a seu país e à humanidade (ONU, 1979, on-line).
\end{abstract}

Dessa forma, constata-se que a eliminação da desigualdade de gênero não representa um benefício apenas para as mulheres, mas sim para toda a sociedade. 0 respeito à diversidade e garantia das liberdades individuais de todos os cidadãos, inclusive das mulheres, constitui elemento fundamental para o desenvolvimento pleno do país.

\section{A INVISIBILIZAÇÃO DA MULHER EM SITUAÇÃO DE PRISÃO}

Que nada nos defina, que nada nos sujeite. Que a liberdade seja a nossa própria substância, já que viver é ser livre.

(Simone de Beauvoir)

A desigualdade de gênero pode ser constatada em diversos contextos, sendo a invisibilização da mulher em situação de prisão apenas um deles. A respeito da condição de invisibilidade, conceitua Eroles, citado por Fernando de Brito Alves (2013, p. 127): "O que caracteriza a vulnerabilidade, da qual decorre a exclusão, é a invisibilidade, eles (os excluídos - grupos minoritários ou vulneráveis) não são levados em conta pelo conjunto da sociedade, ou pelos atores sociais dominantes [...]".

De acordo com o explicitado acima, a vulnerabilidade presente na condição do "ser mulher" é o que acarreta a exclusão social vivenciada por esta. A posição de invisível da mulher, perante a sociedade, eleva-se a outro patamar quando esta comete um crime, agravando a conjuntura da exclusão social feminina.

O próprio Estado, por meio do descaso, contribui com o status de invisibilidade do gênero feminino. Prova do citado é o déficit de 13 mil vagas, registrado pelo Ministério da Justiça (BRASIL, 2014), que se traduz em superlotação 
das unidades penitenciárias femininas, fornecimento de alimentação inadequada, falta de mínimas condições de higiene, inexistência de trabalhos sociais que visem à reinserção da mulher presa e, consequentemente, submissão à vivência em condições sub-humanas.

Apesar dos avanços na coleta de dados sobre o sistema prisional brasileiro, ainda é clara a invisibilidade da mulher em situação de cárcere, podendo ser constatada pela falta de uma análise mais apurada dos dados disponíveis para análise. Tendo sido constatado pelo Informativo da Rede Justiça Criminal como "O silêncio eloquente sobre as mulheres no Levantamento Nacional de Informações Penitenciárias".

Raquel da Cruz Lima, Anderson Lobo da Fonseca e Felipe Eduardo Lázaro Braga, ao analisarem o Levantamento Nacional de 2014/INFOPEN, concluem que há uma omissão de dados sobre as mulheres encarceradas que demonstram sua invisibilidade e reforçam um vício comum na construção de políticas públicas no sistema penitenciário. Ainda segundo os autores, ouve a coleta dos dados, apesar das informações não serem completas, mas "o texto final desse primeiro relatório trouxe apenas 7 referências às características femininas - 7 em 130 possíveis (88 gráficos e 42 tabelas)" (INFORMATIVO..., 2016, p. 8).

No que diz respeito às condições desumanas existentes nos presídios, discorre o criminalista Augusto Thompson (1991, p. 102):

Como os estabelecimentos de entrada são as prisões [...], para as quais, como já vimos, não impõe a legislação a observância de quaisquer requisitos especiais, quer quanto ao tipo de acomodações quer quanto ao regime de operação, torna-se possível (ou não é completamente impossivel) elastecer-lhes a capacidade a limites absurdos e desumanos, muitas e muitas vezes superiores à lotação ideal. Assim, em um alojamento onde caberiam cinco camas, com razoável distância entre elas, de sorte a permitir a colocação de um pequeno armário, podem ser acomodados doze presos, desde que se usem beliches e se suprima o móvel; ou vinte e seis, se todo o mobiliário for eliminado e se fizer com que os hóspedes durmam em um estado inteiriço, a cobrir toda a extensão da cela (sistema usado, v. g., no Presídio de Água Santa, no Rio). Ou, se a área pode suportar cinquenta alojamentos, com dez presos em cada um, torna-se viável nela reco-
Iher uma população de mil e quinhentas ou duas mil pessoas, se, em vez de dividi-la em compartimentos, a autoridade se limita a cerca-la com arame farpado, deixando que os residentes se amontoem no interior, dormindo no chão puro (como ocorria no antigo Galpão, no Rio - hoje Instituto Presídio Evaristo de Morais - até 1967). Se o número de guardas, por diminuto, pode manobrar, apenas, uma população prisional de cem presos, basta adotar 0 expediente de manter os internos trancados nos cubículos dia e noite, privados completamente do sol, para habilitar aquela quantidade de funcionários a custodiar mil e quinhentos. Se a verba de alimentação é suficiente para sustentar quinhentos internos, com duas refeições ao dia, pode-se destiná-la ao dobro, se se fornece uma única refeição diária. E assim por diante ${ }^{6}$.

Cumpre ressaltar que, no caso das mulheres em situação de prisão, além de vivenciarem realidade tal qual a exposta na obra de Thompson, outros fatores

60 trecho da obra transcrita merece algumas atualizações, tendo em vista que este foi editado em 1991. No ano de 2012, o site "Agência Brasil" divulgou uma matéria sobre a recomendação da ONU em fechar o antigo presídio de Água Santa, atual presídio Ary Franco: "O Subcomitê de Prevenção à Tortura (SPT) das Nações Unidas recomendou ao Brasil o fechamento imediato do presídio masculino Ary Franco, no Rio de Janeiro. De acordo com relatório, divulgado hoje (14), a infraestrutura do local é inadequada e não há profissionais suficientes nas áreas de assistência social, saúde e educação. Além disso, há casos de superlotação e tortura. [...] De acordo com os observadores, as celas no Ary Franco são geralmente escuras, sujas, abafadas e infestadas de baratas e outros insetos. A grave superlotação e a manutenção precária das celas resultaram em condições que criaram graves problemas de saúde para os detentos, como micoses e outras doenças da pele e do estômago. Em algumas celas, o subcomitê pôde perceber que o sistema de esgoto dos pisos superiores estava vazando pelo teto e pelas paredes. [...] No Ary Franco, o subcomitê observou que os internos são tratados de maneira continuamente degradante. 0 grupo da ONU recebeu relatos consistentes de maus-tratos, incluindo a destruição de pertences pelos agentes penitenciários. Os internos eram forçados a adotar posições humilhantes durante transferências ou inspeções. Por fim, recebeu também relatos de espancamentos". (JINKINGS, 2012, Notícia: Agência Brasil). Apesar do posicionamento da ONU, a favor do fechamento do referido presídio, até o presente ano de 2015 o presídio Ary Franco continua em pleno funcionamento. No que diz respeito ao Presídio Evaristo Moraes, neste ano de 2015 foi divulgada matéria, a partir de depoimento da Defensoria Pública do Estado, no site de notícias "G1 - Rio de Janeiro": "No Presídio Evaristo de Moraes, em São Cristóvão, na Zona Norte do Rio, há fios soltos nas paredes, sujeira pelo chão, celas escuras e até mesmo baratas. [...] Caixas com restos de comida e lixo se misturam com o local onde os detidos dormem. A cama de cimento está quebrada e os presos improvisam para viver num espaço pequeno. [...] No banheiro é possível observar um local de condições precárias e com muita sujeira. Não há condições básicas para os presos e o banheiro não conta com chuveiro e iluminação. Em outra cela é possível observar mais lixo, restos de comida e um tanque improvisado". (G1, 2015, on-line). Ambos os presídios, citados em 1991 pelo criminalista Thompson, continuam, até os dias atuais, submetendo os detentos a condições precárias e desumanas. 
agravam à falta de estrutura das penitenciárias femininas. A "coisificação" da mulher, por exemplo, remete ao esquecimento de que esta também tem direito à sexualidade e, consequentemente, dificulta as visitas íntimas no presídio. Nesse contexto, esclarece a pesquisadora Olga Espinoza (2004, p. 125):

Também contribui para a separação familiar a quantidade de restrições no exercício do direito à visita íntima. O Regimento Interno Padrão dos Estabelecimentos Prisionais de alguns Estados - como São Paulo - prevê esse direito sem aparente discriminação, porém ele é principalmente exercido nos presídios masculinos [...].

Dessa forma, conclui-se que, na prática, a vida sexual da mulher é vista como secundária em relação à sexualidade masculina. Enquanto esta é encarada como algo natural, proveniente da natureza do homem e necessária para a saúde e bem-estar deste; aquela é vista como algo desnecessário, existente apenas em razão da precisão de reprodução da espécie humana.

Além da sexualidade feminina, outro ponto primordial a ser discutido em relação à desigualdade de gênero, presente no sistema prisional, são os delitos que acarretaram na condenação da maioria das mulheres em situação de prisão. Outrora, os crimes praticados restringiam-se aos chamados "delitos femininos", sendo estes compostos pelos crimes: infanticídio, aborto e homicídio passional. Porém, o cenário vivenciado atualmente sofreu notável abrangência, visto que os crimes de roubo e tráfico também integram o rol de práticas criminosas comuns ao gênero feminino (ESPINOZA, 2004).

A maioria dos crimes praticados por mulheres possuem como objeto o patrimônio, figurando o roubo como delito de maior frequência 7 . Ao analisar o crime de roubo, Foucault critica a forma de aplicação da punição dispensada a este crime:

0 roubo tende a se tornar a primeira das grandes escapatórias à legalidade, nesse movimento que vai de uma sociedade da apropriação jurídico-política a uma sociedade da apropriação dos meios e produtos do trabalho.

7 Com base nos dados do Sistema Nacional de Informações Penitenciárias - INFOPEN dez/12. Disponível em: <https://goo.gl/TO7DMu>. Acesso em: 29 ago.2015

\begin{abstract}
Ou para dizer as coisas de outra maneira: a economia das ilegalidades se reestruturou com o desenvolvimento da sociedade capitalista. A ilegalidade dos bens foi separada da ilegalidade de direitos. Divisão que corresponde a uma oposição de classes, pois, de um lado, a ilegalidade mais acessível às classes populares será a dos bens - transferência violência das propriedades; de outro, a burguesia, então, se reservará a ilegalidade dos direitos: a possibilidade de desviar seus próprios regulamentos e suas próprias leis; de fazer funcionar todo um imenso setor da circulação econômica por um jogo que se desenrola nas margens da legislação - margens previstas por seus silêncios, ou liberadas por uma tolerância de fato. (FOUCAULT, 2013, p. 83).
\end{abstract}

O filósofo francês descreveu em seu texto as formas pelas quais o roubo é punido, relacionando-as com o poder econômico do indivíduo. A classe detentora do poder econômico e político possui a prerrogativa de conduzir os moldes da legislação, possibilitando assim, que a punição para a prática de ilegalidade de direitos, como crimes oriundos da corrupção (desvio de verbas, fraudes, evasões fiscais, entre outros), seja tão somente o pagamento de multas atenuadas. Enquanto, por outro lado, para as ilegalidades de bens - roubo - as penas constituem severos castigos, como a privação da liberdade.

Conforme já citado, os crimes contra o patrimônio figuram em alto índice no rol de delitos praticados por mulheres. A partir desse fato, faz-se necessário analisar o grau de escolaridade das infratoras. De acordo com dados do Ministério da Justiça ${ }^{8}$, aproximadamente $60 \%$ da população carcerária feminina não possui o ensino fundamental completo, demonstrando, assim, a vulnerabilidade social e econômica desse público. A realidade aqui abordada é evidenciada na obra $A$ muIher encarcerada em face do poder punitivo de autoria da pesquisadora Olga Espinoza (2004, p. 127):

[...] a mulher reclusa integra as estatísticas da marginalidade e exclusão: a maioria não é branca, tem filhos, apresenta escolaridade incipiente e conduta delitiva que se caracteriza pela menor gravidade, vinculação com o patrimônio e reduzida participação

\footnotetext{
8 Com base nos dados do Sistema Nacional de Informações Penitenciárias - INFOPEN dez/12. Disponível em: <https://goo.gl/9N6ayzs>. Acesso em: 29 ago.2015
} 
na distribuição de poder, salvo contadas 18exceções. Esse quadro sustenta a associação da prisão à desigualdade social, à discriminação, à seletividade do sistema de justiça penal, que acaba punindo os mais vulneráveis, sob categorias de raça, renda e gênero.

Os ditames da sociedade brasileira refletem-se no Sistema Prisional. Afinal, ambos excluem as minorias, representadas por presos, mulheres, crianças, negros, homossexuais, deficientes, pessoas de baixa condição econômica, entre outros.

\section{MÉTODO APAC NO BRASIL: HISTÓRICO E PRINCÍPIOS}

O principal objetivo da pena privativa de liberdade é promover a reinserção social do autor do crime, de modo que este não volte a delinquir. Para atingir o cumprimento de tal objetivo, mostra-se necessária a oferta de cursos profissionalizantes e educacionais voltados a possibilitar ao presidiário um meio de sustento, dignificando, assim, o indivíduo. Entretanto, cumpre ressaltar que o funcionamento atual do Sistema Prisional não permite a materialização dessa reinserção social.

A referida crise do Sistema Prisional resta explicitada pelo doutrinador Cezar Bitencourt (2011, p. 162):

Quando a prisão converteu-se na principal resposta penológica, especialmente a partir do século XIX, acreditou-se que poderia ser um meio adequado para conseguir a reforma do delinquente. Durante muitos anos imperou um ambiente otimista, predominando a firme convicção de que a prisão poderia ser um meio idôneo para realizar todas as finalidades da pena e que, dentro de certas condições, seria possível reabilitar o delinquente. Esse otimismo inicial desapareceu e atualmente predomina certa atitude pessimista, que já não tem muitas esperanças sobre os resultados que se possam conseguir com a prisão tradicional. A crítica tem sido tão persistente que se pode afirmar, sem exagero, que a prisão está em crise. Essa crise abrange também o objetivo ressocializador da pena privativa de liberdade, visto que grande parte das críticas e questionamentos que se faz à prisão refere-se à impossibilidade - absoluta ou relativa - de obter algum efeito positivo sobre o apenado.
0 intuito de promover a reinserção social do preso, trazido no fundamento da pena de prisão, não se aplica à realidade prática. Conforme aduzido no trecho exposto, há uma impossibilidade de obtenção de efeito positivo sobre o apenado na aplicação da pena privativa de liberdade. Aprisionar o indivíduo em um local superlotado, isolado dos acontecimentos da sociedade, submetendo-o a condições subumanas, sem qualquer perspectiva de vida, não condiz com o objetivo ressocializador.

O Sistema Prisional vigente constitui, portanto, um pseudosistema de reinserção social, visto que não há políticas penitenciárias que desenvolvam qualificação profissional, crescimento espiritual e aproximação do preso com a família. O que ocorre, em verdade, é a total exclusão do indivíduo e a sua submissão a eterna condição de "criminoso", como se isto fosse sua nova pele, sua perpétua identidade.

Muitas foram as tentativas de melhorar esse Sistema Penitenciário excludente e opressor, não apenas no Brasil, com também em diversos países do mundo. Porém, a grande maioria das aparentes soluções não obteve o sucesso esperado, findando-as à curta duração (MARQUES NETO, 2012).

Uma das tentativas de implementar melhorias no Sistema Penitenciário ocorreu em 1972, na cidade de São José dos Campos/SP. Sob a liderança do advogado criminalista Mário Ottoboni, um grupo de voluntários cristãos começou a frequentar o presídio de Humaiatá, com o intuito de fornecer oportunidade de evangelização, como também apoio aos presos. Inicialmente, essa atuação era uma experimentação promovida em razão do alto índice de fugas, violências e rebeliões verificadas no citado estabelecimento prisional (OTTOBONI; FERREIRA, 2004).

A partir dos resultados positivos apresentados pelo grupo de cristãos, verificou-se a necessidade de consolidar e jurisdicionar a atuação desses voluntários. Consequentemente, o então juiz competente das Execuções, Silvio Marques Neto, autorizou a instituição da Associação de Proteção e Assistência aos Condenados (APAC), entidade jurídica sem fins lucrativos, com o objetivo de reestruturar o modo de execução da 
pena, auxiliando na reinserção do preso, na proteção à sociedade e no socorro à vítima, de forma a garantir a justiça (OTTOBONI; FERREIRA, 2004).

A aplicação do Método Apaqueano pauta-se em doze princípios elementares: participação da comunidade, recuperando, auxiliando; trabalho; religião; assistência jurídica; assistência à saúde; valorização humana; família; voluntário e curso de formação; Centro de Reintegração Social (CRS); mérito; e jornada de libertação. Cada um dos fundamentos em tela faz-se indispensável para instituição de unidades APAC (OTTOBONI; FERREIRA, 2004).

A participação da comunidade, responsável pela tarefa de introduzir o método nas prisões, é requisito para o funcionamento de uma APAC. A equipe deve ser formada a partir da qualificação de pessoas da comunidade, as quais devem voluntariar-se. Devido à necessidade de voluntariedade, demonstra-se importante a difusão do projeto por meios de comunicação como, por exemplo, jornais e revistas. Após o processo de "voluntarização”, inicia-se uma verdadeira preparação, por meio de cursos de formação instituídos para ensinar a metodologia e desenvolver aptidões nos voluntariados, visando à concretização do exercício dos trabalhos com eficácia e forte espírito comunitário.

0 auxílio de um, recuperando para com o outro representa mais um ponto de eficácia do método objeto de análise neste trabalho. Uma das características intrínsecas à condição de ser humano é a vida em comunidade, por isso, a convivência e estímulo ao respeito mútuo, promove harmonia no ambiente e proporciona dignidade humana ao indivíduo. Da mesma forma, o trabalho, pautado na qualificação do preso, também o dignifica e auxilia em sua reinserção social.

A religião por si só não constitui elemento suficiente para garantir a reinserção do preso, prova disso são os altos índices de reincidência (entre $75 \%$ e $80 \%$ ) mesmo com o trabalho de grupos religiosos de diferentes credos nos estabelecimentos prisionais (OTTOBO$\mathrm{NI}$; FERREIRA, 2004). Diferentemente do que ocorre nos referidos casos, o Método Apaqueano preocupa-se com a experiência de Deus na vida do apenado, não impondo especificamente esta ou aquela religião.
Garantir ao preso assistência jurídica (a maioria não possui condições financeiras para contratar um advogado), assistência à saúde (médica, odontológica, psicológica) e valorização humana (reformular a autoimagem da pessoa que errou, promovendo uma verdadeira jornada de libertação e início de uma nova história de vida) compõem também importantes requisitos de operacionalização das APAC. A referida valorização humana ocorre, ainda, na execução do princípio do mérito, o qual determina a necessidade de se advertir e elogiar o preso, possibilitando que este se sinta uma pessoa responsável ou até digno de servir como referência para os demais.

Por fim, há o Centro de Reintegração Social destinado a oferecer ao recuperando a convivência com o núcleo afetivo: família, amigos e parentes. Em relação à importância da família no processo de reinserção do preso, aduzem Ottoboni e Ferreira (2004, p. 24):

\begin{abstract}
No método APAC, a família do recuperando é muito importante. Aquilo que o sistema comum rompe, na APAC se faz de tudo para fortalecer, ou seja, é preciso trabalhar para que a pena atinja tão somente a pessoa do condenado, evitando ao máximo que ela extrapole a pessoa do infrator e atinja sua família. Neste sentido, empreende-se um grande esforço para que não se rompam os elos efetivos do recuperando com sua família. Por exemplo: o recuperando pode telefonar uma vez por dia para seus parentes, escrever cartas, etc. No dia dos pais, das mães, das crianças, Natal e outras datas importantes, é permitido que os familiares participem com os recuperando das festividades programadas no presídio.
\end{abstract}

Pode-se, assim, verificar a atenção especial dispensada à convivência e aproximação do preso com sua família no Método Apaqueano. $\mathrm{O}$ apoio dos entes queridos traduz-se em incentivo e força para que o indivíduo tenha esperança e otimismo em iniciar uma nova fase em sua vida.

0 método aqui defendido apresenta índices notoriamente positivos. Por exemplo, de acordo com os dados divulgados pelo Tribunal de Justiça de Minas Gerais (MINAS..., on-line), estima-se que a reincidência entre os egressos das unidades APAC gira em torno de $15 \%$, enquanto os índices de reincidência dos presídios 
alcançam o percentual de $75 \%$. Além do exposto, cumpre destacar o baixo custo de manutenção do referido método. Conforme estatística divulgada pelo citado Tribunal, uma vaga nos estabelecimentos para abrigar os presos (recuperandos) em unidades APAC tem custado 1/3 (um terço) do valor da vaga de uma penitenciária dedicada ao sistema comum (MINAS GERAIS, on-line).

\section{A EXCLUSÃO DA MULHER NO PROCESSO DE IMPLEMENTAÇ̃̃OO DAS APACS NO BRASIL}

De acordo com dados do Tribunal de Justiça do Estado de Minas Gerais (MINAS..., on-line), atualmente existem 39 APAC em funcionamento e 58 em fase de implementação em Minas Gerais. Portanto, há um total de aproximadamente 97 APAC juridicamente instituídas (PORTAL..., on-line), dentre as quais, somente 7 são femininas. Nos Estados do Espírito Santo, Paraná, Rio Grande do Sul, Mato Grosso, Maranhão, Rio Grande do Norte e no Distrito Federal, não existem unidades femininas.

Ao considerar o fato de que $7 \%$ da população carcerária brasileira referem-se a mulheres, nota-se a discrepância em números quando comparada à população carcerária masculina. Caso fosse estipulada como meta a implementação de mais unidades APAC femininas, o número visivelmente menor de mulheres presas permitiria a comprovação de sucesso do Método Apaqueano. Afinal, um quantitativo menor possibilita maior efetividade quanto à administração de novos procedimentos.

Soma-se à justificativa citada, a influência das relações pessoais na inserção das mulheres no contexto de criminalidade.

No crime de tráfico, por exemplo, praticado por um grande percentual das reclusas, o grau de responsabilidade assumido pela mulher na estrutura de poder é insignificante (ESPINOZA, 2004). Em outras palavras, apesar de autoras do citado crime, elas atuam como auxiliares de menor importância, sendo os responsáveis pela estruturação de toda conduta criminosa, seus companheiros, filhos, maridos, irmãos, entre ou- tros. Comprova-se, portanto, a influência das relações sociais na inserção de mulheres no mundo do crime.

Dessa forma, ao analisar o perfil das reclusas, resta clara a compatibilidade da mulher em situação de prisão com o método APAC. Os dados do Levantamento Nacional de Informações Penitenciárias (BRASIL, 2014) constataram que o perfil etário das mulheres encarceradas segue a regra feral, jovens com idade abaixo de 34 anos, no auge da sua capacidade produtiva (economicamente ativo) e com baixo grau de escolaridade. Quanto aos crimes praticados, $68 \%$ das mulheres encarceradas foram presas pela prática do crime de tráfico de drogas, sendo que apenas $2 \%$ delas praticaram o crime de roubo qualificado pelo resultado morte (Latrocínio).

Entretanto, numa sociedade conservadora e patriarcal, não se faz prioridade o interesse por causas femininas. Nesse sentido, aduz a filósofa feminista Judith Butler (2015, p. 79):

Para Lévi-Strauss, a identidade cultural masculina é estabelecida por meio de um ato aberto de diferenciação entre clãs patrilineares, em que a "diferença" nessa relação é hegeliana - isto é, distingue e vincula ao mesmo tempo. Mas a "diferença" estabelecida entre os homens e as mulheres que efetivam a diferenciação entre os homens escapa completamente a essa dialética. Em outras palavras, o momento diferenciador da troca social parece ser um laço social entre os homens, uma união hegeliana em termos masculinos, simultaneamente especificados e individualizados. Num nível abstrato, trata-se de uma identidade-na-diferença, visto que ambos os clãs retêm uma identidade semelhante: masculinos, patriarcais e patrilineares. Ostentando nomes diferentes, eles particularizam a si mesmos no seio de uma identidade cultural masculina que tudo abrange. Mas que relação institui as mulheres como objeto de troca, inicialmente portadoras de um sobrenome e depois de outro?

O trecho extraído da obra feminista "Problemas de Gênero" esclarece que a cultura masculina, concretizada por meio de uma sociedade patriarcal, possui grande poder de abrangência social. No presente contexto, esse caráter abrangente, que se fortifica por meio da submissão da mulher a posições e participações sociais inferiores e de menor importância, influi diretamente no desinteresse estatal em relação 
às mulheres em situação de prisão, como também na visível exclusão da mulher quanto à implementação do método APAC em unidades femininas.

Encontra-se exemplo da referida invisibilização na aplicabilidade da Lei de Execução Penal. De acordo com o artigo 41, XII, da Lei 7210/84 (Lei de Execução Penal) ${ }^{9}$, constitui direito do preso ser tratado com igualdade. Cumpre ressaltar que o citado dispositivo se refere ao princípio constitucional da igualdade, ou seja, tratar aos iguais com igualdade e aos desiguais com desigualdade. Dessa forma, a mulher deveria receber um tratamento específico para o gênero feminino, no que se refere à saúde e higiene, o que não ocorre nas penitenciárias. Do mesmo modo, também não há previsão desse tratamento específico da mulher no regulamento das APAC.

Outro ponto a ser destacado é a inexistência de um recorte de gênero nos princípios norteadores das APAC. Por exemplo, ao tratar do requisito de assistência à saúde, não existe nenhuma menção à assistência ginecológica nas unidades apaqueanas femininas. Apesar das doenças, provenientes da inexistência de acompanhamento ginecológico, constituírem situação comum nos estabelecimentos prisionais, não há a discussão de políticas públicas que garantam a proteção à saúde da mulher.

Um método humanizado de execução penal, que cumpre os princípios e a Lei de Execuções Penais, as Regras Mínimas das Nações Unidas para o Tratamento de Presos (Regras de Mandela) ${ }^{10}$ e os demais Tratado de Diretos Humanos Internacionais, incentivado pela ONU, através da Prison Fellowship International (PFI), órgão consultivo da Organização das Nações Unidas (ONU) em assuntos penitenciários, deve ampliar sua atuação para atender as diferenças de gênero, humanizando os espaços de cumprimento de penas para as mulheres encarceradas.

9 Art. 41, Lei 7210/84: “Constituem direitos do preso: [...] XII - igualdade de tratamento salvo quanto às exigências da individualização da pena".

10 Após conferência 55 anos da edição das "Regras Mínimas para o Tratamento de Presos", utilizado para orientar os países signatários na execução de medidas privativas e na estruturação de seus sistemas judiciais de justiça, em especial a justiça penal, em 2015 as Nações Unidas, através da Resolução $75 / 175$ de 17 de dezembro de 2015, atualizou todo quadro normativo sobre o tema, incorporando os princípios dos novos Tratados de Direitos Humanos, sendo esta nova versão denominada de Regras de Mandela.

\section{CONCLUSÃO}

Os presídios brasileiros apresentam altos índices de reincidência e péssimas condições estruturais. Em análise específica apenas das penitenciárias femininas, além dos pontos citados, há também a inobservância de questões femininas, como por exemplo: a necessidade de disponibilização periódica do exame Papanicolau, de absorventes, entre outros fatores referentes à saúde e higiene próprias do gênero feminino.

A partir do exposto, resta claro que as detentas são submetidas a condições ainda piores que os homens presos. Afinal, o tratamento da mulher em situação de prisão não observa questões específicas do gênero. Em outras palavras, as unidades femininas duplicam a violência para com as presidiárias ao tratá-las como se homens fossem.

Conforme demonstrado neste trabalho, a maioria dos crimes cometidos pelas reclusas apresenta baixo índice de violência. Além disso, os delitos são praticados, em sua grande maioria, em coautoria com irmãos, namorados, companheiros, entre outros, demonstrando, assim, a influência das relações pessoais na inserção dessas mulheres no mundo do crime. A partir do exposto, constata-se o baixo grau de periculosidade das presas, o que confirma a possibilidade de aplicação do método Apaqueano como solução eficaz para o caos existente nas penitenciárias femininas. Porém, o descaso estatal para com a mulher em situação de prisão surge como obstáculo para concretização de medidas como a aqui relatada.

Dessa forma, percebe-se que a invisibilização vivenciada pela mulher ultrapassa as grades da prisão e atingem, inclusive, métodos humanos de reinserção, como o método aqui tratado, das APACs. Prova disso é o fato de não haver qualquer recorte de gênero nos princípios que norteiam o Método Apaqueano, igualando a mulher, mais uma vez, ao homem. 0 fato do número de homens presos ser absolutamente maior, deveria ser norteador e facilitador do reconhecimento dos direitos fundamentais da mulher encarcerada.

Faz-se necessária a busca pelo enfrentamento à desigualdade de gênero, de modo a dar maior visibilida- 
de para a mulher em todas as situações, o que inclui o âmbito prisional. A correta aplicação do método APAC, considerando as questões próprias do gênero feminino, representa uma possível saída para a desumanidade presenciada atualmente em diversas unidades femininas. Precisa-se, portanto, fomentar as discussões que tratam da mulher como autora de crimes, objetivando-se, com isso, maior visibilidade da questão. Essa visibilidade traria diversos avanços para as mulheres em situação de prisão, como, por exemplo, a implementação de um maior número de unidades APAC femininas.

\section{REFERÊNCIAS}

ALAMBERT, Zuleika. Feminismo: o ponto de vista marxista. São Paulo: Nobel, 1986.

ALVES, Fernando de Brito. Constituição e participação popular: a construção históricodiscursiva do conteúdo jurídico-político da democracia como direito fundamental. Curitiba: Juruá, 2013.

BITENCOURT, Cezar Roberto. Falência da pena de prisão: causas e alternativas. 4.ed. São Paulo: Saraiva, 2011.

BRASIL. Constituição (1988). Constituição da República Federativa do Brasil. Brasília, DF: Senado, 1988.

\section{BRASIL. Convenção sobre a Eliminação de todas as \\ Formas de Discriminação contra a Mulher - ONU, 1979.}

\section{BRASIL. MINISTÉRIO DA JUSTIÇA. Levantamento} nacional de informações penitenciárias - INFOPEN/ Mulheres. Junho 2014. Disponível em: <https://goo. $\mathrm{gl} / \mathrm{qt} 5 \mathrm{gzc}>$. Acesso em: 13 fev. 2017.

BUTLER, Judith P. Problemas de gênero: feminismo e subversão da identidade. 8.ed. Tradução: Renato Aguiar. Rio de Janeiro: Civilização Brasileira, 2015.
ESPINOZA, Olga. A mulher encarcerada em face do poder punitivo. São Paulo: IBCCRIM, 2004.

FOUCAULT, Michel. Vigiar e punir: nascimento da prisão. Tradução de Raquel Ramalhete. 41.ed. Petrópolis, RJ: Vozes, 2013.

\section{G1. Defensoria Pública divulga fotos do estado} precário dos presídios do RJ. 2015. Disponível em: <https://goo.gl/iGc6rq>. Acesso em: 20 fev. 2017.

INFORMATIVO REDE JUSTIÇA CRIMINAL n 8. Jan/2016. Disponível em: <https://goo.gl/Y55u0r>. Acesso em: 13 fev. 2017.

JINKINGS, Daniella. ONU recomenda fechamento do Presídio Ary Franco no Rio de Janeiro. Agência Brasil, 2012. Disponível em: <https://goo.gl/ jHHu40>. Acesso em: 23 mar. 2015.

MARQUES NETO, Silvio. Do condenado e do internado. In: SILVA, Jane Ribeiro (Org). A execução penal à luz do método APAC. Belo Horizonte: Tribunal de Justiça do Estado de Minas Gerais, 2012. p.25-35.

MINAS GERAIS. Tribunal de Justiça. Programa Novos Rumos - Metodologia APAC. Disponível em: < https://goo.gl/xrCZe9>. Acesso em: 8 out.2016.

ONU. REGRAS MÍNIMAS DAS NAÇÕES UNIDAS PARA O TRATAMENTO DE PRESOS (REGRAS DE MANDELA). Resolução 70/175 da AssembleiaGeral, anexo, adotada a 17 de dezembro de 2015. Disponível em: <https://goo.gl/Br7Fl2>. Acesso em: 23 mar.2017.

OTTOBONI, Mário; FERREIRA, Valdeci Antonio. Parceiro da ressurreição: Jornada de libertação com Cristo e curso intensivo de conhecimento e aperfeiçoamento do método APAC, especialmente para presos. São Paulo: Paulinas, 2004. 
PORTAL FRATERNIDADE BRASILEIRA DE ASSISTEENCIA AOS CONDENADOS. Disponível em: $<$ http://www.fbac.org.br/index.php/pt/apac-s/ contato-2>. Acesso em: 25 jan. 2017.

ROSSI, Celina Fraga. Feminismo ou Femismo? São coisas completamente diferentes. Disponível em: <https://goo.gl/9Tgkh4 />. Acesso em: 10 ago. 2015.
SEN, Amartya. Desenvolvimento como Liberdade. São Paulo: Companhia das Letras, 2000.

THOMPSON, Augusto. A questão penitenciária. Rio de Janeiro: Forense, 1991.
Recebido em: 17 de setembro de 2016 Avaliado em: 12 de março de 2017 Aceito em : 22 de março de 2017

\begin{abstract}
1 Mestranda em Ciência Jurídica pela Universidade Estadual do Norte do Paraná - UENP; Graduada em Direito pela Universidade Tiradentes (2015) - UNIT; Integrante dos grupos de pesquisa: Execução Penal; e Gênero, Família e Violência do Diretório de Pesquisa do CNPq. E-mail: brunnarsantiago@hotmail.com

2 Doutorando em Direito pela Universidade Presbiteriana Mackenzie - UPM; Mestre em Direito pela Pontifícia Universidade Católica do Paraná - PUC/PR; Vice-líder do Grupo de pesquisa em Execução Penal - Diretório de Pesquisa do CNPq; Associado pleno do Fórum Brasileiro de Segurança Pública - FBSP; Professor da Universidade Tiradentes e Delegado de Polícia Civil do Estado de Sergipe. E-mail: ronaldo_ marinho@outlook.com.br
\end{abstract}


